\title{
Mediastinal impalement with a fibreglass sheet
}

Welege Samantha Buddhika Wimalachandra ${ }^{1}$, MBBS, Atasha $\underline{\text { Asmat }}^{2}$, FRCs

\begin{abstract}
Mediastinal impalement injuries are uncommon and often fatal. There have been very few reported cases of survival following mediastinal impalement. Patients who present with these injuries always undergo operative intervention regardless of their underlying haemodynamic status or associated injuries. We herein present a case of mediastinal impalement injury, where a sheet of fibreglass had fractured the manubrium and entered the anterior mediastinum with no associated great vessel injury. The fibreglass sheet was removed via a partial sternotomy and the patient made an uneventful postoperative recovery.
\end{abstract}

Keywords: impalement injury, mediastinum, thoracic

\section{INTRODUCTION}

Impalement injuries, in which a foreign body traverses or penetrates a body cavity or extremity in a through-and-through fashion and remains in place, can result in a dramatic clinical picture. Mediastinal impalement injuries are uncommon and often fatal because of the injury to the underlying organs within the mediastinum. We herein report a case where a fragmented fibreglass sheet fractured the manubrium and penetrated the anterior mediastinum with no underlying injuries. The fibreglass sheet was removed without complications at surgery.

\section{CASE REPORT}

A 24-year-old man was cutting a piece of fibreglass sheet with a grinder when an explosion occurred, causing the sheet to fragment. A piece of the fragment penetrated the anterior part of his chest over the sternum (Fig. 1). He was transferred to the accident and emergency department of a local hospital, where he was noted to be alert with stable haemodynamic parameters and no neurological symptoms. Computed tomography of the chest revealed a foreign body penetrating the anterior chest wall and causing a comminuted fracture of the manubrium. The tip of the foreign body was in the mediastinal fat and appeared to be abutting the right innominate artery and left innominate vein (Fig. 2).

The patient was transferred to our hospital with the fibreglass sheet in his chest. He was brought emergently to the operating room for removal of the fibreglass sheet. The penetrating wound was extended to incorporate the upper half of the sternum in the midline, and a partial sternal split was performed for easy removal of the foreign body (Fig. 3). We noted a mediastinal haematoma, no injury to the right innominate artery or left innominate vein, and intact pleurae. The mediastinum and wound were irrigated with copious amounts of warm saline and the sternum (including the fractured manubrium) was closed with sternal wires. The wound was closed in layers, and skin closure was done using interrupted vertical mattress sutures. The patient made an uneventful recovery and was discharged on Day 4 postsurgery. He was reviewed in

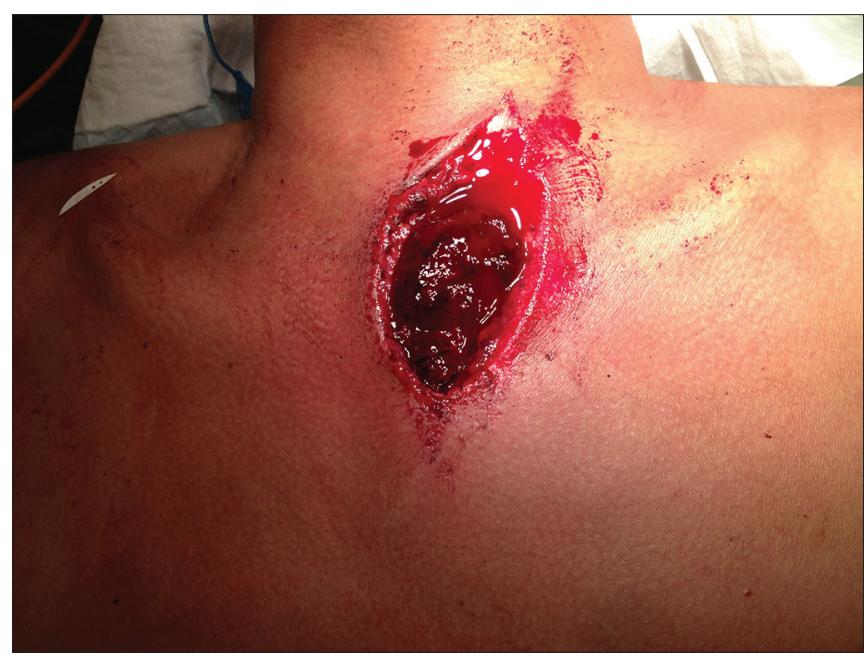

Fig. 1 Photograph shows the open anterior chest wall wound with the fibreglass sheet in situ.

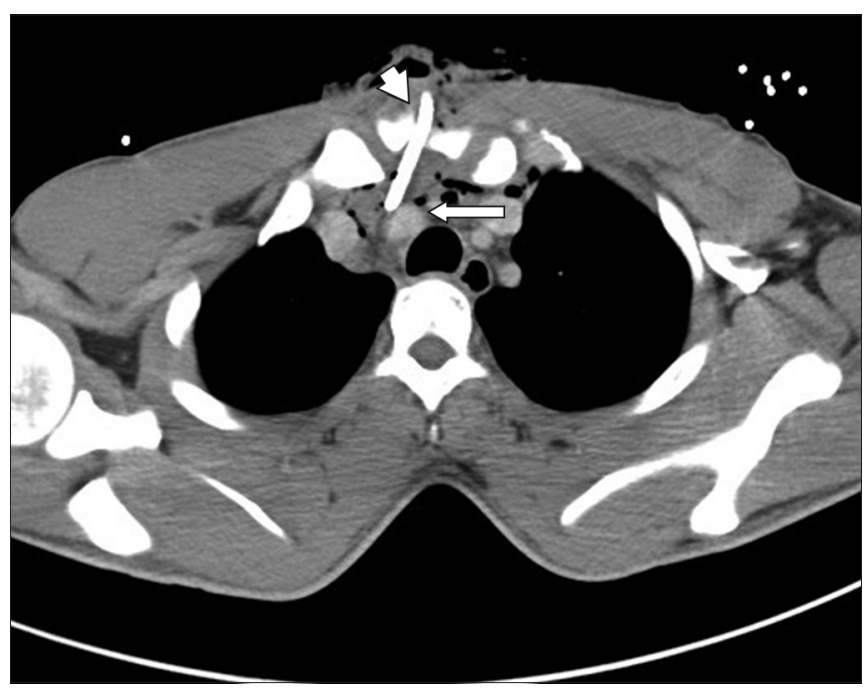

Fig. 2 Axial CT image shows the foreign body traversing the manubrium (arrowhead) and resting within the anterior mediastinum, and the tip of the foreign body abutting the right innominate artery (arrow).

the outpatient clinic a month later, where it was noted that his wound had healed and he had returned to work.

${ }^{1}$ Department of Surgery, ${ }^{2}$ Formerly from the Department of Cardiac, Thoracic and Vascular Surgery, National University Hospital, Singapore

Correspondence: Dr Atasha Asmat, Associate Consultant, Division of Thoracic Surgery, Department of General Surgery, Tan Tock Seng Hospital, 11 Jalan Tan Tock Seng, Singapore 308433. atasha_asmat@ttsh.com.sg 


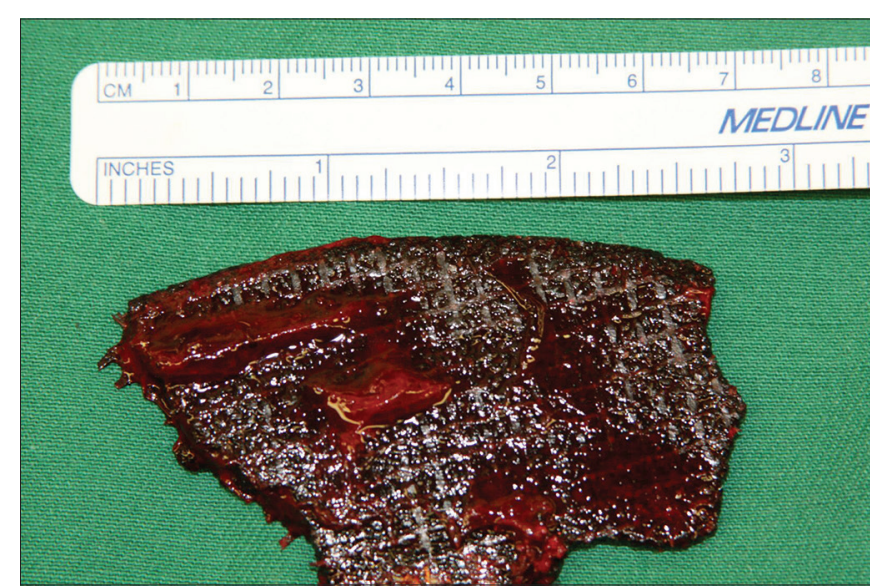

Fig. 3 Photograph shows the removed fibreglass sheet, measuring $7 \mathrm{~cm}$ in length.

\section{DISCUSSION}

Impalement injuries combine aspects of blunt and penetrating trauma, with the degree of damage sustained being dependent on the organs involved. ${ }^{(1)}$ An impalement injury to the mediastinum is potentially lethal due to the presence of major vascular and visceral organs within the mediastinum. ${ }^{(2)}$
The most important principle in the management of patients with mediastinal impalement injuries is to leave the impaled foreign object in situ. Once the usual trauma management principles have been followed, removal of the impaled object should be performed within a well-controlled environment such as an operating theatre. The wound should be adequately exposed and the foreign body removed under direct vision to prevent uncontrolled haemorrhage. Once the foreign body has been removed, a thorough evaluation of the operative field is necessary, as the associated injuries previously not visible with the object in situ may become evident. The wound should be adequately irrigated and debrided to minimise the risk of infection.

In conclusion, mediastinal impalement injuries are rare. However, an understanding of the underlying management principles of these types of injuries may aid in improving outcomes for the small number of patients who present to the emergency department with such injuries.

\section{REFERENCES}

1. Hyde MR, Schmidt CA, Jacobson JG, Vyhmeister EE, Laughlin LL. Impalement injuries to the thorax. Ann Thorac Surg 1987; 43:189-90

2. Burack JH, Kandil E, Sawas A, et al. Triage and outcome of patients with mediastinal penetrating trauma. Ann Thorac Surg 2007; 83:377-82. 